\title{
BIOFERTILIZANTE DE ESTERCO BOVINO NA INDUÇÃO DE MECANISMOS DE DEFESA À MELOIDOGYNE INCOGNITA NA CULTURA DA SOJA
}

\section{CATTLE BIOFERTILIZER IN THE INDUCTION OF DEFENSE MECHANISMS TO MELOIDOGYNE INCOGNITA IN SOYBEAN CULTURE}

\author{
Jessica Brasau Da Silva ${ }^{1}$ \\ Juliana Santos Batista Oliveira ${ }^{2}$ \\ Camila Jorge B. Ferreira ${ }^{3}$ \\ Antônio Jussiê Da Silva Solino ${ }^{4 *}$ \\ Kátia R. F. Schwan-Estrada ${ }^{5}$
}

\begin{abstract}
Resumo
O objetivo deste trabalho foi avaliar o controle de Meloidogyne incognita e a ativação de mecanismos de defesa de plantas em função de diferentes métodos de aplicação de biofertilizante de esterco bovino (BIO). Para isto foi conduzido um experimento para avaliar a porcentagem de eclosão (PE) do nematoide com dois tratamentos, água e BIO, com dez repetições. Um segundo experimento foi conduzido em casa de vegetação em esquema fatorial $2 \times 3+1$ com seis repetições. O fator A (água e BIO) e fator B (aplicação via solo (S), pulverizado (PUL) e a combinação S + PUL), além da testemunha (sem inoculação do patógeno) como tratamento adicional. Foram avaliados o número de ovos (NO) e juvenis (NJ) de $M$. incognita na raiz, atividade específica de catalase (CAT), peroxidase (POX) e polifenoloxidase (PFO) no sistema radicular e parte aérea da cultura. A PE de $M$. incognita foi $65 \%$ inferior em solução com BIO, in vitro. In vivo, a aplicação de $\mathrm{BIO}$ reduziu o $\mathrm{NO}$ e NJ. Ao aplicar o BIO via $\mathrm{S}$, observou-se incremento de até 1,8 vezes da CAT e 35 vezes da POX em folhas. A POX foi incrementada em até 1,7 vezes no sistema radicular. O biofertilizante bovino apresentou potencial no controle $M$. incognita.
\end{abstract}

Palavras-chave: Glycine max, indução de resistência, nematoide.

\begin{abstract}
The objective of this work was to evaluate the control of Meloidogyne incognita and activate the defense mechanism of the plants in functions of different methods of application of bovine manure biofertilizer (BIO). For this, an experiment was conducted to evaluate the percentage of nematode
\end{abstract}

\footnotetext{
${ }^{1}$ Mestranda egressa do Programa de Pós-graduação em Agronomia da Universidade Estadual de Maringá, UEM, fone: (44) 99820-8155, e-mail: jessicabrasau@ gmail.com

${ }^{2}$ Pós-doutoranda do Programa de Pós-graduação em Agronomia da Universidade Estadual de Maringá, UEM, fone: (44) 99922-1985, e-mail: julianaglomer@ hotmail.com

${ }^{3}$ Pós-graduanda em Agronomia da Universidade de Rio Verde, UniRV, fone: (44) 99704-7936, e-mail: camilajbferreira@gmail.com

4 Dr. Pesquisador da De Lollo Pesquisa e Experimentação Agrícola, fone: (64) 99918-1875, e-mail: jussiesolino@ hotmail.com (autor correspondente)

${ }_{5}^{5}$ Prof $^{a}$. Dr ${ }^{a}$ orientadora, bolsista CNPq, PROFAGROEC da Universidade Estadual de Maringá, UEM, fone: (44) 998275668, e-mail: krfsestrada@uem.br
} 
hatched $(\mathrm{PH})$ with two treatments, water and $\mathrm{BIO}$, with ten replicates. A second experiment was conducted in the greenhouse in a factorial scheme $2 \times 3+1$ with six replicates. Factor A (water and BIO) and factor B (application via soil (S), pulverized (PUL) and a combination S + PUL), besides a control (without inoculation of the pathogen) as additional treatment. Were evaluated the number of eggs (NE) and juveniles (NJ) of nematode unknown root, specific activity of catalase (CAT), peroxidase (POX) and polyphenoloxidase (PFO) in the root system and in leaves. An pH of $M$. incognita was $65 \%$ lower in solution with $\mathrm{BIO}$, in vitro. In vivo, a $\mathrm{BIO}$ application reduces $\mathrm{NE}$ or NJ. When applying BIO via $S$, it can increase up to 1.8 times the CAT and 35 times the POX in leaves. A POX was increased up to 1.7 times in the root system. The bovine biofertilizer showed potential for $M$. incognita control.

Keywords: Glycine max, resistance induction, nematode.

\section{INTRODUÇão}

A exploração agrícola transformou o Brasil em um grande exportador agrícola mundial, sendo a soja a principal cultura econômica neste cenário, com produção de 115,17 milhões de toneladas obtidas na safra de 2018/2019 (CONAB, 2019). Entretanto, a cultura é atacada por diversas doenças, como, antracnose, ferrugem asiática, mancha foliar de cercospora, podridão radiculares, pústula bacteriana e nematoides, os quais podem comprometer até $32 \%$ da produtividade (SAVARY et al., 2019; YADAY et al., 2020).

Entre os fitonematoides, Heterodera glycines, Meloidogyne incognita, M. javanica, Pratylenchus brachyurus e Rotylenchulus reniformis, que atacam a cultura da soja no Brasil, os do gênero Meloidogyne se destacam em função da ampla ocorrência e gama de hospedeiro, além da alta agressividade, causando perdas significativas na produtividade, comprometendo até $52 \%$ do rendimento de grãos (CARNEIRO et al., 2019; FONTANA et al., 2018; ALMEIDA et al., 2016). Os sintomas das plantas de soja atacadas pelo fitonematoide do gênero Meloidogyne caracterizam-se por redução do comprimento das raízes, que se tornam anormais e com presença de galhas, danos diretos. A parte aérea também expressa sintomas indiretos ou reflexo, como mal desenvolvimento, amarelecimento, clorose e murcha em condições de expresse hídrico (FONTANA et al., 2018).

As estratégias integradas de controle mais utilizadas para reduzir a população de nematoides são o uso de medidas como evitar a entrada do patógeno na área de cultivo, uso 
de cultivares resistente ou tolerantes, aplicação em sulco de plantio ou tratamento de sementes com produtos químicos (nematicidas) e biológicos (agentes de biocontrole), eliminação de plantas hospedeiras na entre safra, rotação com culturas não hospedeiras ou plantas antagônicas, nutrição equilibrada e enriquecimento do solo com matéria orgânica (UPAMALI et al., 2020; FONSECA et al., 2018; DEBIASI et al, 2016; SILVA et al., 2016; VEDOVETO et al., 2013; ARAÚJO et al., 2012; INOMOTO et al., 2011; NUNES et al., 2010).

O esterco animal, compostagem, derivados de plantas, resíduos de plantas gerados animal ou agrícola podem ser utilizados no controle de fitonematoides (UPAMALI et al., 2020; SANTOS et al., 2016), visto que estes podem atuar como fonte nutricional, sendo observado a redução efetiva de nematoides e a promoção de desenvolvimento das plantas (OLIVEIRA et al., 2014; SANTOS et al., 2013; OKA, 2010).

Os adubos orgânicos e/ou biofertilizantes de origem animal e vegetal promovem melhoria da estabilidade de agregados, porosidade do solo, condutividade elétrica, capacidade de troca de cátions, macro e micronutrientes, além de reduzir a densidade do solo, melhorar sua relação $\mathrm{C} / \mathrm{N}$, o que culmina no aumento da resistência de plantas ao ataque de patógenos como nematoides (SCOTTI et al., 2015; LARNEY e ANGERS, 2012; OKA, 2010). Estes ainda podem liberar substâncias tóxicas com ação nematicida (compostos derivados de glucosinolato, ácidos orgânicos, compostos nitrogenados e outros), promover o aumento da comunidade e atividade microbiana, como agentes de biocontrole, com ação antagonista, competitiva ou parasitária (Arthrobotrys e Monacrosporium) de fitonematoides e que podem ativar os mecanismos de defesa da planta (D'ADDABBO et al., 2019; SILVA et al., 2018; OKA, 2010; AKHTAR et al., 2000).

O Brasil foi maior exportado de bovino de corte além de importante produtor de leite, o que consequentemente gerou muitos dejetos bovinos, que durante a transformação energética pode se tornar uma fonte poluidora, quando não realizado o manejo e destinação correta desse material, como por exemplo transformá-lo em biofertilizante utilizados na produção agrícola de alimentos (FAO, 2020; IBGE, 2020; ADEGBEYE et al., 2019; PALERMO et al., 2014 SANTOS e NOGUEIRA, 2012). O biofertilizante bovino é recomendo como fonte complementar nutricional de cereais, melhorando a fertilidade do solo, além de aumentar o teor de matéria orgânico e a atividade microbiológica (DAS et al., 2017; GIL et al., 2008). 
Além dos benefícios para o solo, os biofertilizante de esterco bovino são de fácil aquisição e aplicação, e tem ainda a possibilidade de ser combinado com outros insumos como fertilizantes químicos ou microrganismos benéficos, os quais devem ser considerados no manejo fitonematoides na cultura da soja. Desta forma, o objetivo deste trabalho foi avaliar o controle de Meloidogyne incognita e a ativação de mecanismos de defesa na cultura da soja em função de diferentes métodos de aplicação de biofertilizante bovino.

\section{Material e Métodos}

Foram instalados dois experimentos, sendo um in vitro e outro in vivo, conduzidos respectivamente no laboratório de Indução de Resistência e em casa de vegetação do Departamento de Agronomia, da Universidade Estadual de Maringá, Maringá, PR.

O biofertilizante de esterco bovino (BIO), produto patenteado da empresa Microgeo ${ }^{\circledR}$, foi coletado de uma área de produtor rural da região. Este foi preparado utilizando $15 \%$ de esterco bovino, não curtido, em $85 \%$ de água deionizada e esterilizada. A solução foi homogeneizada por agitação em intervalo de três dias durante 15 dias, quando foi utilizada para instalar os experimentos in vitro e in vivo. $\mathrm{O}$ experimento de avaliação do controle de eclosão de juvenis in vitro, foi instalado em delineamento inteiramente casualizado com dois tratamentos: biofertilizante bovino diluído a $15 \%$ em água (BIO) e controle (água), com 10 repetições.

Antes da instalação do experimento, foram quantificados ovos de população pura de $M$. incognita em câmera de Peters e calibrado em uma suspensão de 400 ovos $\mathrm{mL}^{-}$ 1. Posteriormente uma alíquota de $1 \mathrm{~mL}$ da suspensão foi adicionada à microtubos contendo $1 \mathrm{~mL}$ do tratamento. Os microtubos foram, então, fechados e acondicionados em câmera incubadora tipo B.O.D. a $25^{\circ} \mathrm{C}$ no escuro por 10 dias, quando foi realizada a contagem do número de juvenis eclodidos e calculado a porcentagem de eclosão.

No experimento in vivo foi utilizado o delineamento inteiramente ao acaso em esquema fatorial com um tratamento adicional $2 \times 3+1$, com seis repetições, conforme a descrição dos tratamentos apresentadas no Quadro 1.

Quadro 1. Tratamentos utilizados no ensaio de controle $M$. incognita em função de diferentes métodos de aplicação de biofertilizante bovino na cultura da soja em casa de vegetação

\begin{tabular}{|c|c|}
\hline Ingrediente & Metodo de aplicașào \\
\hline \multicolumn{2}{|c|}{ Goxulado com $M$. incogrita } \\
\hline Água & Suloo de plantio (S) \\
\hline Água & Pulverizacdo parte irea (PCL) \\
\hline Água & $\mathrm{s}+\mathrm{PUI}$ \\
\hline Biofer tilizante bonino a $15 \%$ (BIO) & Sulco de plantio (S) \\
\hline Biofertilizante borino is $15 \%$ (BIO) & Pulverizaçio parte área (PCL) \\
\hline Biofertilizante bovino a $15 \%$ (BIO) & S+PUI \\
\hline \multicolumn{2}{|c|}{ Trat am eato adicional para quantificaç̧o enzim ittica } \\
\hline Sen tratam erto 0 & No inocul ado com $M$ incognito \\
\hline
\end{tabular}


$\mathrm{Na}$ instalação do experimento in vivo, foram semeadas sementes de soja da cultivar 5D6215 IPRO $^{\circledR}$ em copos de isopor (uma semente por copo) contendo $500 \mathrm{~mL}$ de uma mistura de solo e areia (na proporção 2:1), esterilizados em autoclave durante 2 horas a $120^{\circ} \mathrm{C}$. A aplicação dos tratamentos em sulco de plantio (S) foi realizada com auxílio de micropipeta, adicionando $5 \mathrm{~mL}$ por sulco com $2 \mathrm{~cm}$ de diâmetro e $0,5 \mathrm{~cm}$ de profundidade, e em seguida realizada a semeadura, com cobertura das sementes. A aplicação via pulverização (PUL) foi realizada aos 14 dias após a germinação das plantas, utilizando 2,5 $\mathrm{mL}$ da solução de BIO a 15\% e água destilada por repetição, com auxílio de um borrifador. Ao aplicar o tratamento S + PUL, considerouse a aplicação simultânea em sulco e pulverização da parte aérea, seguindo a mesma metodologia e concentração desses tratamentos conforme descrito anteriormente.

A inoculação do patógeno foi realizada no momento da semeadura, aplicando no sulco de plantio $5 \mathrm{~mL}$ de uma suspensão contendo de 400 juvenis de $M$. incognita $\mathrm{mL}$ água $^{-1}$ no segundo estádio (J2) em todos os tratamentos, exceto o tratamento adicional que não recebeu a inoculação. Para multiplicação das populações de Meloidogyne foi utilizado tomateiro cv. Santa Cruz, com 20 dias de idade. Utilizou-se como inoculo suspensão de $5 \mathrm{~mL}$ contendo 800 ovos $\mathrm{mL}^{-1}$, de uma população de $M$. incognita, procedente do Laboratório de Nematologia da Universidade Estadual de Maringá. As plantas inoculadas foram mantidas em condições de casa de vegetação da Universidade Estadual Maringá. As variáveis analisadas foram: número de ovos e juvenis g raiz ${ }^{-1}$, atividade específica de catalase, peroxidase e polifenoloxidase na raiz e parte aérea das plantas de soja. A determinação do número de ovos e juvenis de $M$. incognita foram realizadas aos sessenta dias após a emergência da cultura. A extração de $M$. incognita foi realizada conforme metodologia proposta por Hussey e Barker (1973), adaptado por Bonetti e Ferraz (1981), no qual o sistema radicular foi lavado, pesado, fragmentado em pedaços de 5 cm e triturado em liquidificador, contendo 500 $\mathrm{mL}$ de solução de água e hipoclorito de sódio a $0,5 \%$ durante 20 segundos. Posteriormente, a solução foi vertida sobre jogo de peneiras de 25, 100 e 500 mesh. A suspensão de nematoides retidos na peneira de 500 mesh foi então utilizada para quantificação de juvenis e ovos de $M$. incognita, com auxílio da câmera de Peters, dados em número de juvenis ou ovos por grama de raiz.

Para quantificação da atividade enzimática foram coletadas amostras radiculares e foliares sete dias após a emergência das plântulas de soja que receberam o tratamento adicional (sem 
inoculação), água e BIO aplicado via sulco de plantio (S). Após a coleta, as amostras foram em papel alumínio e armazenadas a $-20^{\circ} \mathrm{C}$ em freezer, para posterior extração e quantificação enzimática.

Para a obtenção do extrato enzimático o tecido vegetal, folhas e raízes foram maceradas separadamente em almofariz utilizando nitrogênio líquido. Ao macerado foi adicionado $4 \mathrm{~mL}$ de solução tampão fosfato de potássio $50 \mathrm{mM}(\mathrm{pH} 7,0)$ contendo 0,1 mM EDTA e $1 \%$ (p/p) de PVP (poli-vinilpirrolidona). $\mathrm{O}$ produto obtido, foi centrifugado a $15.000 \mathrm{~g} \mathrm{e} 4{ }^{\circ} \mathrm{C}$ durante $30 \mathrm{~min}$ e o sobrenadante, considerado como extrato enzimático, foi condicionado em microtúbulos e armazenados a $-20{ }^{\circ} \mathrm{C}$, para posterior quantificação de proteínas totais, peroxidase de guaiacol, catalase e polifenoloxidase analisadas em duplicata.

A determinação de proteínas totais foi realizada pelo teste de Bradford (1976), e expressa em $\mathrm{mg}$ proteína $\mathrm{mL}^{-1}$. Para determinação de peroxidase de guaiacol utilizou-se a metodologia de Lusso e Pascholati (1999), em absorbância $\mathrm{min}^{-1} \mathrm{mg}^{-1}$ de proteína. A quantificação da enzima catalase foi realizada seguindo a metodologia modificado por Tamanková et al. (2006) e proposta por Góth (1991), expressos em $\mu$ mol $\min ^{-1} \mathrm{mg}^{-1}$ proteína. Atividade da polifenoloxidase foi determinada pela mensuração da conversão do catecol em quinona, reação mediada pela enzima polifenoloxidase, segundo a metodologia proposta por Duangmal e Apenten (1999), expressos em absorbância $\min ^{-1} \mathrm{mg}^{-1}$ de proteína.

Os dados dos ensaios in vitro foram submetidos à análise de variância e as médias comparadas pelo teste $\mathrm{T}$ de Fisher utilizando o programa estatístico SISVAR ( $p<0,05)$. Os dados do número de ovos e juvenis de $M$. incognita foram submetidos à análise de variância e as médias foram comparadas pelo teste de Tukey $(\mathrm{p}<0,05)$ programa estatístico ASSISTAT, considerando o esquema fatorial sem tratamento adicional. Os dados enzimáticos foram submetidos à análise de variância e as médias comparadas pelo teste de Tukey programa estatístico ASSISTAT, considerando o esquema fatorial com tratamento adicional, aplicação de água esterilizada sem inoculação de $M$. incognita (p $<0,05)$.

\section{RESULTADOS}

A porcentagem de eclosão de $M$. incognita foi $65 \%$ inferior ao incubar ovos em solução com $15 \%$ de BIO, avaliação do controle de eclosão de juvenis in vitro, quando comparado ao controle (Figura 1). 


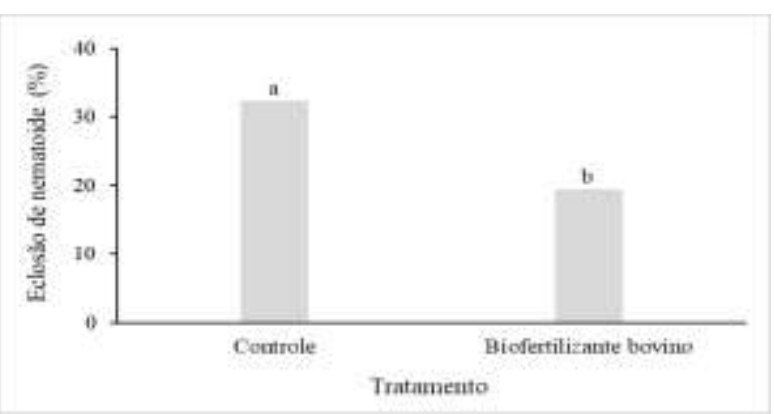

Figura 1. Porcentagem de eclosão de Meloidogyne incognita em função da incubação de ovos em solução de biofertilizante bovino. Médias seguidas de mesma letra não diferem entre si pelo teste $\mathrm{T}$ de Fisher ( $\mathrm{p}<$ $0,05)$. CV $=24 \%$.

Ao analisar o efeito dos tratamentos sobre a população de $M$. incognita em plantas de soja, observou-se que a aplicação do BIO via PUL, S e S + PUL reduziram, 66, 40 e $85 \%$ número de ovos por grama de raiz, respectivamente, quando comparado aos respectivos tratamentos utilizando água (Figura 2A). Nos desdobramentos dos métodos de aplicação dentro dos tratamentos, aplicação do BIO em combinação S + PUL foi superior ao método de aplicação via PUL, não diferindo do S (Figura 2A).

$\mathrm{O}$ uso de BIO reduziu o número de juvenis em 90, 51 e $62 \%$ pelos métodos de aplicação S, PUL e S + PUL, respectivamente, quando comparados aos seus controles utilizando somente água (Figura 2B). Ao desdobrar os métodos de aplicação dentro do tratamento BIO, observou-se que S + PUL foi superior a PUL e não diferiu do método $\mathrm{S}$ (Figura 2B).

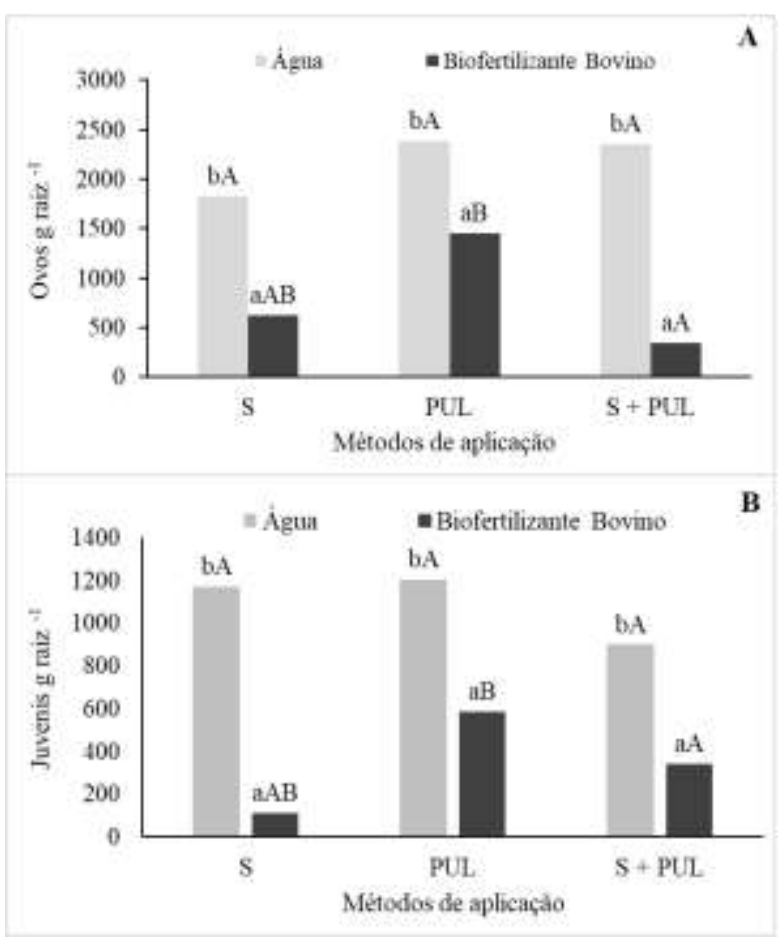

Figura 2. Número de ovos (A) e juvenis (B) de Meloidogyne incognita em raiz de plantas de soja em função da aplicação de biofertilizante bovino via sulco (S), pulverização (PUL) e em combinação $\mathrm{S}+$ PUL. $\mathrm{CV}(\mathrm{A})=38 \%$ e $\mathrm{CV}(\mathrm{B})=25 \%$. $*$ Médias seguidas de mesma letra minúscula comparam os tratamentos e maiúsculas comparam os métodos de aplicação pelo teste de Tukey $(\mathrm{p}<0,05)$.

Ao aplicar o BIO via sulco (S), observou-se incrementou 1,8 vezes a atividade da catalase (CAT) na parte aérea da cultura da soja, quando comparado ao controle inoculado e não inoculado com $M$. incognita, entretanto não houve diferença na atividade da enzima na raiz (Figura 3A). 


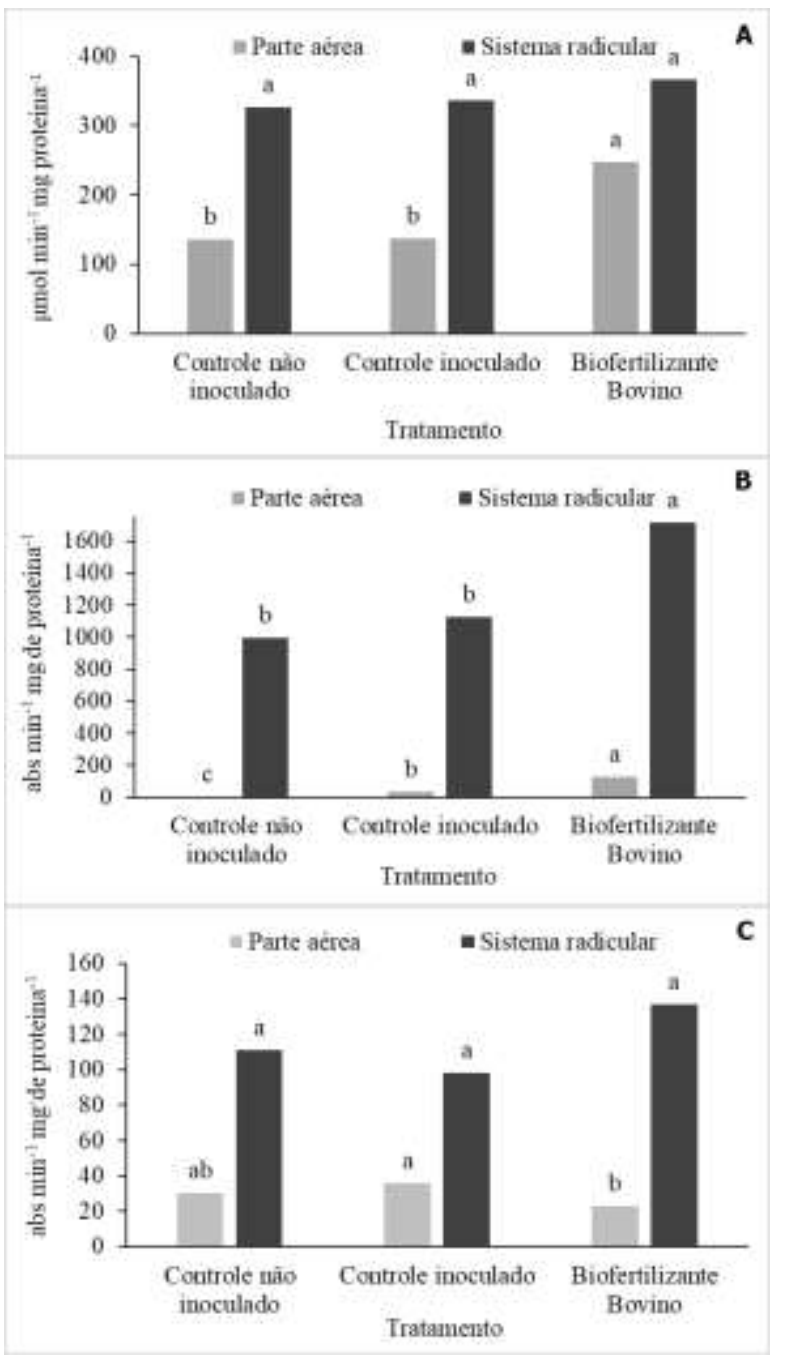

Figura 3. Atividade de catalase (A), peroxidase (B) e polifenoloxidase (C) na parte aérea e sistema radicular de soja aos sete dias após a emergência em função da aplicação de biofertilizante bovino no sulco de plantio (S). $\mathrm{CV}(\mathrm{A})$ : raiz $=18 \%$ e folha $=14 \% ; \mathrm{CV}(\mathrm{B}):$ raiz $=17 \%$ e folha $=15 \%$; e CV $(\mathrm{C})$ : raiz $=23 \%$ e folha $=28 \%$. $*$ Médias seguidas de mesma letra não diferem entre si pelo teste de Tukey $(\mathrm{p}<0,05)$.

A atividade da peroxidase (POX) foi incrementada 35 e 3,5 vezes na parte aérea de soja ao aplicar o BIO via S, quando comparado ao controle sem e com inoculação de $M$. incognita, respectivamente (Figura 3B). A atividade da POX também foi incrementada 1,7 e 1,5 vezes no sistema radicular ao aplicar DOI: http://dx.doi.org/10.24021/raac.v18i1.5346 o BIO quando comparado ao controle sem e com inoculação de $M$. incognita, respectivamente (Figura 3B).

$\mathrm{A}$ atividade de polifenoloxidase (PFO) foi reduzida na parte aérea ao aplicar o BIO em sulco, quando comparados ao tratamento controle (não inoculado e inoculado). A PFO não foi influenciada no sistema radicular (Figura 3C).

\section{DISCUSSÃo}

A porcentagem de eclosão in vitro de ovos de $M$. incognita foi reduzida $65 \%$ após 10 dias de incubação em BIO a 15\%, indicando ação nematicida ou nematostática na sua composição. A ação nematostática de biofertilizante de esterco animal também foi relatada por Xiao et al. (2008), que observaram redução da eclosão de Heterodera glycines, quando ovos foram incubados em biofertilizante suíno. Osei et al. (2011) também observaram que extratos de resíduos orgânicos de plantas e esterco de frango são capazes de reduzir a eclosão de até $100 \%$ de M. incognita.

A ação nematicida observada pelo esterco animal bruto e/ou biofertilizante orgânicos de origem animal ou vegetal, como BIO no controle da eclosão de $M$. incognita, pode estar relacionada a presença de ácidos húmicos, ácidos fúlvicos, ácidos orgânicos, derivados de glicosinolato, compostos 
nitrogenados, compostos derivados de glicosídeo e outras substâncias presente na composição. Entretanto, isto depende de diversos fatores, tais como: composição, origem, processo de fermentação, realização de enriquecimento com microrganismo, nutrientes e material orgânico de outra fonte, entre outros (BALACHANDAR et al., 2020; HOSSAIN e AKTER, 2020; D'ADDABBO et al., 2019; SILVA et al., 2018; DAS et al., 2017; SANTOS et al., 2016; OKA, 2010),

No ensaio in vivo, as aplicações de BIO realizadas via $\mathrm{S}$ e $\mathrm{S}+\mathrm{PUL}$ promoveram o maior controle de ovos e juvenis de $M$. incognita por grama de raiz, quando comparado ao controle e PUL, indicando que este é o método mais eficaz para o controle de M. incognita nas condições avaliadas. Este efeito pode estar ligado a ação nematicida ou nematostática direta, como observado no experimento in vitro. No entanto, este controle também pode estar relacionado no aumento de número de populações de microrganismos com ação antagonista, competitiva ou parasitária de $M$. incognita e as alterações físico-química do solo, além das mudanças fisiológicas da planta, como nutricional e indução de resistência das plantas (D’ADDABBO et al., 2019; SILVA et al., 2018; OKA, 2010; AKHTAR et al., 2000).

Ao analisar as mudanças fisiológicas das plantas de soja tratadas com BIO via $\mathrm{S}$, observou-se incremento da atividade da POX na parte aérea e principalmente no sistema radicular. Isto se deve a capacidade que as plantas possuem de reconhecer moléculas de natureza biótica e abiótica, como padrões moleculares de microrganismos patogênicos (M. incognita) e não patogênicos (antagonista, competitiva, parasitária, endofíticos e outros), nutrientes, substâncias húmicas e outras (MALIK et al., 2020; CALDERIN GARCIA et al., 2014; MIRANSARI, 2011; VIDHAYASEKARAN 2020). Assim, a ativação da POX pela BIO indica que este possui em sua composição moléculas elicitoras ou promove alterações no solo de ordem nutricional e biológica que podem ser reconhecidas pelo sistema de defesa da soja.

O envolvimento da POX enzina na resistência de soja a Meloidogyne está correlacionada a plantas que respondem mais rápido a infecção por nematoides, aumentando o acúmulo de peróxido de hidrogênio $\left(\mathrm{H}_{2} \mathrm{O}_{2}\right)$ e em consequência a atividade da peroxidase, indicando o papel relevante desta na defesa de plantas contra patógenos, como M. incognita, observado neste trabalho (FARAHAT et al., 2015; SIAHPOUSH et al., 2011; SHARON et al., 2001; MELILLO et al., 1992).

$\mathrm{O}$ incremento da atividade da peroxidase observado na parte área e principalmente no sistema radícula da soja, 
permite indicar um aumento no acúmulo de $\mathrm{H}_{2} \mathrm{O}_{2}$, de forma indireta, na célula vegetal, visto que estas enzimas estão envolvidas na reação de dismutacão de $\mathrm{H}_{2} \mathrm{O}_{2}$ em água e oxigênio, reduzindo o estresse oxidativo causado pelo patógeno ou pelo agente elicitor (BHATT e TRIPATHI, 2011). As EROs têm papel fundamental no processo de defesa, atuando diretamente na reação de hipersensibilidade e morte da célula, impedindo o avanço do patógeno, ou atuando indiretamente como molécula sinal para eventos subsequentes na defesa vegetal (DALLAGNOL et al., 2018; RESENDE et al., 2003; LIHARSKAI E WILLIAMSON, 1997). Além da ação direta da $\mathrm{H}_{2} \mathrm{O}_{2}$, o aumento da POX observado em plantas de soja tratada com BIO, pode ter contribuído para o controle do $M$. incognita, visto que o resulta da detoxificação desta ERRO, culmina lignificação e suberização das células radiculares, dificultando a formação de sítios de infecção de Meloidogyne (ZACHEO et al., 1997; BALHADÈRE e EVANS, 1995; ZACHEO et al., 1995; ZACHEO e BLEVEZACHEO, 1995; HAMMERSCHMIDT, 1992).

Os tratamentos via parte área podem reduzir o de ovos e juvenis de $M$. incognita por grama de raiz, como observado neste estudo, ao aplicar o biofertilizante bovino via PUL ou em combinação $S+$ PUL. Entretanto, a aplicação deste em via $S$ aumentou o potencial de controle do $M$. incognita, quando comparado a PUL, em função da associação dos fatores de ação nematicida/nematostática direta ou indiretamente, alterando o sistema biológico e a fertilidade do solo, bem como nutrição e fisiologia da planta de soja, comprovado pelo aumento da POX. Segundo Santana-Gomes et al. (2013), a nutrição vegetal deve ser considerada um fator importante na relação patógeno-hospedeiro, bem como uma ferramenta de gerenciamento de fitonematoides, visto que o fornecimento destes aumenta a resistência a doenças e tolerância em função do maior vigor.

O Biofertilizante de esterco bovino promoveu controle do $M$. incognita de forma direta in vitro e in vivo, ao reduzi a eclosão de ovos e número de ovos e juvenis na raiz quando aplicado via sulco de plantio, além ativar sistema de defesa das plantas de soja ao incrementar a atividade de peroxidase do guaiacol.

\section{AgRAdecimentos}

A Universidade Estadual de Maringá e Microgeo $^{\circledR}$.

\section{REFERÊNCIAS}

ADEGBEYE MJ, REDDY PRK, OBAISI AI, ELGHANDOUR MMMY., OYEBAMIJI KJ, SALEM AZM, MORAKINYO-FASIPE OT; 
CIPRIANO-SALAZAR M; CAMACHODÍAZ, LM. Sustainable agriculture options for production, nutritional mitigation of greenhouse gasses and pollution, and nutrient recycling in emerging and transitional nations - An overview. Journal of Cleaner Production, Lund, v. 242, n.1, p. 1-21, 2019.

ARAUJO FF de, BRAGANTE RJ, BRAGANTE CEl. Controle genético, químico e biológico de meloidoginose na cultura da soja. Pesquisa Agropecuária. Tropical, Goiânia, v. 42, n. 2, p.220-224, 2012.

ALMEIDA FAA, CARVALHO RMC, LEITE MLT, FONSECA WL, PEREIRA FFP. Reação de cultivares de soja aos nematoides das galhas. Revista Ciências Agrárias, Belém, v. 59, n. 3, p. 228-234, 2016.

AKHTAR M, MALIK A. Roles of organic soil amendments and soil organisms in the biological control of plant-parasitic nematodes: a review. Bioresource Technology, Palampur, v. 74, n.1, p. 35-47, 2000 .

ARRUDA CAO, ALVES MV, MAFRA A, CASSOL PC, ALBUQUERQUE JA, SANTOS JCP. Aplicação de dejeto suíno e estrutura de um latossolo vermelho sob semeadura direta. Ciência e agrotecnologia, Lavras, v. 34, n. 4, p. 804-809, 2010.

BHATT I, TRIPATHI BN. Plant peroxiredoxins: catalytic mechanisms, functional significance and future perspectives. Biotechnology Advances, Hanover, v. 29, p. 850-859, 2011.

\section{BALACHANDAR R, BASKARAN L,} YUVARAJ A, THANGARAJ R, SUBBAIYA R, RAVINDRAN B, CHANG SW, KARMEGAM N. Enriched pressmud vermicompost production with green manure plants using Eudrilus eugeniae. Bioresource
Technology, Palampur, v. 219, n. 1, p. 1-47, 2020.

BALHADÈRE P, EVANS AAF. Cytochemical investigation of resistance to root-knot nematode Meloidogyne naasi in cereals and grasses using cryosections of roots. Fundamental \& applied Nematology, Wageningen, v. 18, n. 6, p. 539-547, 1995.

BONETTI JI, FERRAZ S. Modificações do método de Hussey \& Barker para extração de ovos de Meloidogyne exigua em raízes de cafeeiro. Fitopatologia Brasileira, Brasília, v. 6, n.1, p. 553, 1981.

BRADFORD MM. A rapid and sensitive method for the quantitation of microgram quantities of protein utilizing the principle of protein-dye binding. Analytical Biochemistry, Orlando, v. 72, p. 248-254, 1976.

CARNEIRO GE de S, DIAS WP, FOLONI JSS, MOREIRA A, SANTOS JCF, SOUZA CF de B, SILVA NETO SP, PEREIRA AF. Comportamento de genótipos de soja em área naturalmente infestada com Meloidogyne incognita. In: Anais da $37^{\mathbf{a}}$ Reunião de Pesquisa de Soja, Londrina, 2019. p. 112115.

CONAB - Companhia Nacional de Abastecimento. Acompanhamento da Safra Brasileira: V. 7 - SAFRA 2018/19. Brasília: Companhia Nacional de Abastecimento CONAB, v. 6, p. 1-100, 2019.

D'ADDABBO T, LAQUALE S, PERNIOLA $\mathrm{M}$, CANDIDO V. Biostimulants for plant growth promotion and sustainable management of phytoparasitic nematodes in vegetable crops. Agronomy, New York, v. 9, n. 10 , p. 616 - 626, 2019.

DALLAGNOL JL (Org). Resistência genética: de plantas a patógenos. Pelotas: Ed. UFPel, 2018. $437 \mathrm{p}$. 
DAS S, JEONG ST, DAS S, KIM PJ. Composted cattle manure increases microbial activity and soil fertility more than composted swine manure in a submerged rice paddy. Frontiers in Microbiology, Lausanne, v. 8, n. 1702, 2017.

DEBIASI H, FRANCHINI J C, DIAS WP, RAMOS JUNIOR EU, BALBINOT JUNIOR AA. Práticas culturais na entressafra da soja para o controle de Pratylenchus brachyurus. Pesquisa Agropecuária Brasileira, Brasília, v. 51, n. 10, p. 1720-1728, 2016.

DIAS-ARIEIRA CR, FERRAZ S, FREITAS LG, MIZOBUTSI EH. Seleção de gramíneas forrageiras para o controle de Meloidogyne incognita e M. javanica. Acta Scientiarum. Agronomy, Maringá, v. 25, n. 2, p. 473-477, 2003.

DUANGMAL K, APENTEN RKO. A comparative study of polyphenoloxidases from taro (Colocasia esculenta) e potato (Solanum tuberosum var. Romano). Food Chemistry, Barking, v. 64, p. 351-359, 1999.

FAO - Food and Agricultural commodities production. Top 20 Country, Export quantity of Meat, cattle, boneless (beef \& veal) 2019. Disponível em: <http://www.fao.org/faostat/en/\#rankings/co untries_by_commodity_exports>. Acesso em: 08 de julho de 2019.

FARAHAT AA, AL-SAYED AL-SA, AFIFY AM, MAHFOUD NM. Inducing resistance in eggplant against Meloidogyne incognita by organic and inorganic fertilizers, plant growth regulators and amino acids. Egyptian Journal Agronematology, Cairo, v. 14, n. 1, p. $91-115,2015$.

FONSECA WL, ALMEIDA FA de, LEITE MLT, OLIVEIRA AM de, PROCHNOW JT, RAMOS L da L, RAMBO RP, ALCÂNTARA NETO F de, PEREIRO FF,
CARVALHO RM. Influence of manipueira on Meloidogyne javanica in soybean. Revista de Ciências Agrárias, Recife, v. 41, n. 1, p.191-200, 2018.

FONTANA L. Interference of Meloidogyne javanica in the reproduction of Pratylenchus brachyurus in soybean cultivar BRS/MT pintado. Summa phytopathologica, Botucatu, v. 44, n. 2, p. 143-147, 2018.

GARCÍA A, GURIDI IZQUIERDO F, BERBARA RLL. Effects of humic materials on plant metabolism and agricultural productivity. In: AHMAD P, RASOOL S. Emerging technologies and management of crop stress tolerance, 1. ed. San Diego: Elsevier Science Publishing Co Inc, 2014, v. 1. 592p. p. 449-466.

GIL MV, CARBALLO MT, CALVO LF. Fertilization of maize with compost from cattle manure supplemented with additional mineral nutrients. Waste Management, Amsterdam, v. 28, n. 8, p. 1432-1440, 2008.

GOTH L. A simple method for determination of serum catalase activity and revision of reference range. Clinica Chimica Acta, Amsterdam, v. 196, n. 2-3, p. 143-151, 1991.

HOSSAIN S, AKTER F. Effects of trichoderma-enriched biofertilizer and farmyard manure on the growth and yield of brinjal (Solanum melongena L.). Dhaka University Journal of Biological Sciences, Dhaka, v. 29, n. 1, p. 1-8, 2020.

HUSSEY RS, BARKER KR. A comparison of methods colleting inocula of Meloidogyne spp. including a new technique. Plant Disease Reporter, Washington, v. 57, p. 1025-1028, 1973.

IBGE - Instituto Brasileiro de Geografia e Estatística. Produção da Pecuária Municipal. Conjunto de tabelas sobre os estabelecimentos agropecuários levantados 
pelo Censo Agropecuário 2017. Disponível em:

$<$ https://www.ibge.gov.br/estatisticas/econo micas/agricu

ltura-e-pecuaria/21814-2017-censo-

agropecuario.html? $=\& \mathrm{t}=$ resultados $>$. Acesso em: 09 de junho de 2020.

INOMOTO MM, SIQUEIRA KMS, MACHADO ACZ. Sucessão de cultura sob pivô central para controle de fitonematoides: variação populacional, patogenicidade e estimativa de perdas. Tropical Plant Pathology, Brasília, v. 36, n. 3, p. 178-185. 2011.

LARNEY FJ, ANGERS DA. The role of organic amendments in soil reclamation: A review. Canadian Journal of Soil Science, Ottawa, v. 92, n. 1938. 2012.

LIHARSKA TB, WILLIAMSON VM. Resistance to root knot nematodes in tomato. In: FENOLL C, GRUNDLER FMW, OHL SA. (Eds.). Cellular and Molecular Aspects of Plant-Nematode Interactions, 1. ed. Berlim: Kluwer Academic Puclishers Springer, 1997. V. 1, 300p. p. 191-200.

LUSSO MFG, PASCHOLATI SF. Activity and isoenzymatic pattern of soluble peroxidases in maize tissues after mechanical injury or fungal inoculation. Summa Phytopathologica, Botucatu, v. 25, n. 3, p. 244-249, 1999.

MALIK NAA, KUMAR IS, NADARAJAH $\mathrm{K}$. Elicitor and receptor molecules: orchestrators of plant defense and immunity. International Journal of Molecular Sciences, Basel, v. 21, n. 963, p. 1-34.

MIRANSARI M. Soil microbes and plant fertilization. Applied Microbiology and Biotechnology, Munster, v. 92, n. 5, p.875885, 2011.
NAHAR MS, GREWAL PS, MILLER SA, STINNER D, STINNER BR, KLEINHENZ MD, WSZELAKI A, DOOHAN D. Differential effects of raw and composted manure on nematode community, and its indicative value for soil microbial, physical and chemical properties. Applied Soil Ecology, Amsterdam, v. 34, p. 140-151, 2006.

NICHOLSON RL, HAMMERSCHMIDT R. Phenolic compounds and their role in disease resistance. Annual Review of Phytopathology, Palo Alto, v. 30, p. 369-389, 1992.

NUNES HT, MONTEIRO AC, POMELA AWV. Uso de agentes microbianos e químico para o controle de Meloidogyne incognita em soja. Acta Scientiarum Agronomy, Maringá, v. 32, n. 3, p. 403-409, 2010.

OKA Y. Mechanisms of nematode suppression by organic soil amendments - A review. Applied Soil Ecology, Amsterdam, v. 44, p. 101-115, 2010.

OLIVEIRA LB, ACCIOLY AMA, SANTOS CLR, FLORES RA, BARBOSA FS. Características químicas do solo e produção de biomassa de alface adubada com compostos orgânicos. Revista Brasileira de Engenharia Agrícola e Ambiental Campina Grande, Campina Grande, v.18, n.2, p.157164, 2014.

OSEI K, ADDICO R, NAFEO A, EDUKWARTENG A, AGYEMANG A, DANSO Y, SACKEY-ASANTE J. Effect of some organic waste extracts on hatching of Meloidogyne incognita eggs. African Journal of Agricultural Research, AgoIwoye, v. 6, n. 10, p. 2255-2259, 2011.

PALERMO GC, D'AVIGNON AL de A, FREITAS, MAV. Reduction of emissions from brazilian cattle raising and the generation of energy: intensification and 
confinement potentials. Energy Policy, Amsterdam, v. 68, n.1, p. 28-38, 2014.

RESENDE MLV, SALGADO SML, CHAVES ZM. Espécies ativas de oxigênio na resposta de defesa de plantas a patógenos. Fitopatologia brasileira, Brasília, v. 28, n. 2, p. 123-130, 2003.

SANTANA-GOMES $S$ de $M$, DIASARIEIRA CR, ROLDI M, DADAZIO TS, MARINI PM, BARIZÃO DA de O. Mineral nutrition in the control of nematodes. African Journal of Agricultural, Ago-Iwoye, v. 8, n. 21, p. 2413-2420, 2013.

SHARON E, BAR-EYAL M, CHET I, HERRERA-ESTRELLA A, KLEIFELD O, SPIEGEL Y. Biological control of the rootknot nematode Meloidogyne javanica by Trichoderma harzianum. Biological Control, San Diego, v. 91, n. 7, p. 687-93 2001.

SANTOS BHC, RIBEIRO RCF, XAVIER AA, SANTOS NETO JA, MOTA VJG. Controle de Meloidogyne javanica em mudas de bananeira 'prata-anã' por compostos orgânicos. Revista Brasileira de Fruticultura, Jaboticabal, v. 35, n. 2, p. 650656, 2013.

SANTOS IA dos, NOGUEIA AH. Estudo energético do esterco bovino: seu valor de substituição e impacto da biodigestão anaeróbia. Revista Agroambiental, Boa Vista, v. 1. n. 1, p. 41-49, 2012.

SANTOS JF, SILVA SCS, SOARES ACF, LIMA OFS, BARBOSA DHSG. Actinobacteria and organic fertilizers for management of the nematode Scutellonema bradys in yam plants. Revista Caatinga, Mossoró, v. 29, n. 3, p. 548 - 558, 2016.

SANTOS JQ. Agricultura biológica e fertilização. Revista de Ciências Agrárias, Recife, v. 35, n. 1, p. 49-58, 2012.
SAVARY S, WILLOCQUET L, PETHYBRIDGE SJ, ESKER P, MCROBERTS N, NELSON A. (2019). The global burden of pathogens and pests on major food crops. Nature Ecology \& Evolution, London, v. 1, n. 1, p. 1-10, 2019.

SCOTTI R, BONANOM, G, SCELZA R, ZOINA A, RAO MA. Organic amendments as sustainable tool to recovery fertility in intensive agricultural systems. Journal of Soil Science and Plant Nutrition, Araucanía, v 15, n. 2, p. 333-352, 2015.

SIAHPOUSH S, SAHEBANI N, AMINIAN $\mathrm{H}$. Change of some defense compounds of cucumber treated with Bacillus cereus and salicylic acid against Meloidogyne javanica. African Journal of Plant Science, AgoIwoye, v. 5, n. 14, p. 829-834, 2011.

SILVA FJ, RIBEIRO RCF, XAVIER AA, SANTOS NETO JA, SOUZA MA, DIASARIEIRA CR. Rizobactérias associadas a materiais orgânicos no controle de nematoides das galhas em tomateiro. Horticultura Brasileira, Brasília, v. 34, p. 059-065, 2016.

SILVA JCP da, MEDEIROS FHV de, CAMPOS VP. Building soil supprressiveness against plant-parasitic nematodes. Biocontrol Science and Technology, Abingdon, v. 1, n. 1, p. 1-23, 2018.

TOMÁNKOVÁ K, LUHOVÁ L, PETRIVALSKY M, PEC P, LEBEDA A. Biochemical aspects of reactive oxygen species formation in the interaction between Lycopersicon spp. and Oidium neolycopersici. Physiological and Molecular Plant Pathology, London, v. 68, n. 1, p. 22-32, 2006.

TONINATO BO, SOUZA DHG, PONTALTI PR, LOPES APM, DIAS-ARIEIRA CR. Meloidogyne javanica control in lettuce with fertilizers applied isolated or associated with 
biological product. Horticultura Brasileira, Brasília, v. 37: p. 384-389, 2019.

UPAMALI P; PEIRES S; LI Y; BROWN P; XU C. Efficacy of organic amendments to control Meloidogyne spp. in crops: a systematic review and meta-analysis. Journal of Soils and Sediments, Hamburg, v. 20, n. 1, p. 584-1598, 2020.

WACHIRA PM, KIMENJU JW, OKOTH SA, MIBEY RK. Stimulation of nematodedestroying fungi by organic amendments applied in management of plant parasitic nematode. Asian Journal Plant Science, Faisalabad, v. 8, n. 2, p.153-159, 2009.

VAN DER WESTHUIZEN AJ, QIAN XM, BOTHA AM. Differential induction of apoplastic peroxidase and chitinase activities in susceptible and resistant wheat cultivars by Russian wheat aphid infestation. Plant Cell Reports, Belmont, v. 18, n. 1-2, p. 132-137, 1998.

VEDOVETO MVV, DIAS-ARIEIRA, CR, RODRIGUES DB, ARIEIRA JO, ROLDI M, SEVERINO JJ. Adubos verdes no manejo de Pratylenchus brachyurus em soja. Nematropica, Gainesville, v. 43, n. 2, p. 226232, 2013.

VEECH JA, ENDO BY. The Histochemical localization of several enzymes of soybeans infected with the root-knot nematode Meloidogyne incognita acrita. Journal of Nematology, Hanover, v. 1, n. 3, p. 265-276, 1969.

VIDHYASEKARAN, P. (Ed.). Plant innate immunity signals and signaling systems. Bioengineering and molecular manipulation for crop disease management. 1. ed. India: Springer. $217 \mathrm{p}$.

XIAO J, CHEN S, ZHU J, RUAN W. Effect of liquid swine manure on hatch and viability of Heterodera glycines. Journal of
Nematology, Hanover, v. 40, n. 2, p. 152160. 2008.

YADAV YK, KHARE CP, TIWARI PK, SRIVASTAVA JN. Important disease of soybean crop and their management. In: SRIVASTAVA JN., SINGH AK (ed.). Disease of field crops diagnosis and managent: pulses, oil seeds, narcotics and sugar crop. 1 ed. New Jersey: Apple Academic Press, v. 2, 2020, 399p. chapter 9.

ZACHEO G, BLEVE-ZACHEO T, MELILLO MT. Biochemistry of plant defence responses to nematode infection. In: FENOLL C, GRUNDLER FMW, OHL SA (Eds.). Cellular and Molecular Aspects of Plant-Nematode Interactions. Dordrecht: Springer, 1. ed. 1997, 300p. p. 201-213.

ZACHEO G, BLEVE-ZACHEO T, PACODA D, ORLANDO C, DURBIN RD. The association between heat-induced susceptibility of tomato to Meloidogyne incognita and peroxidase activity. Physiological and Molecular Plant Pathology, London, v. 46, n. 6, p. 491-507, 1995.

ZACHEO G, ORLANDO C, BLEVEZACHEO T. Characterization of Anionic Peroxidases in Tomato Isolines Infected by Meloidogyne incognita. Journal of Nematology, Hanover, v. 25, n. 2, p. 249256, 1993.

(Mestrado em Zoologia) - PUCRS. Porto Alegre, 1993.

Submissão: 31/03/2020.

Aceito: 10/01/2021. Publicado: 05/03/2021. 